\title{
Migración africana y formación social en las Américas, $1500-2000$
}

\author{
por \\ José C. Moya \\ Barnard College \\ Columbia University
}

Unos 11 millones de africanos llegaron al Nuevo Mundo entre 1500 y 1866 en lo que constituye la primera migración masiva transoceánica en la historia de la humanidad. Este artículo estudia ese movimiento desde la perspectiva de la historia de las migraciones y formaciones socio-raciales en las Américas. La primera parte establece el origen, ritmo temporal y distribución geográfica de las llegadas empleando una base de datos que contiene información sobre unos 35.000 viajes de barcos negreros. Sobre esta base, se analiza el impacto demográfico, el desarrollo socioeconómico, la presencia cultural africana, las estrategias de adaptación y aculturación, y la construcción de taxonomías e identidades raciales en las regiones receptoras.

Palabras Clave: Migración; Américas; África; esclavitud; raza.

La presencia africana en las Américas se asocia automáticamente con la esclavitud, pero la trata transatlántica también constituye la primera migración transcontinental masiva en la historia del hemisferio y de la humanidad ${ }^{1}$. Los nueve millones de africanos que llegaron a las Américas entre 1492 y 1800 más que triplican el número de inmigrantes europeos durante la época. Dos millones más llegaron entre la supuesta abolición de la trata, declarada por el gobierno británico en 1807, y mediados de siglo. El hecho de que este movi-

1 El tráfico de esclavos del este de África a través del Sáhara y el Océano Índico hacia el Medio Oriente alcanzó cifras similares (unos diez millones) a las del tráfico transatlántico pero el movimiento fue menos masivo pues empezó cinco siglos antes y duró un siglo más. Wright, 2007. 
miento se dirigió a regiones donde la población aborigen era exigua, o había desaparecido como grupo cultural, amplificó su impacto demográfico, económico y sociocultural ${ }^{2}$. Hoy día el número de afro-descendientes en las Américas se estima en 180 millones y estos representan la mayoría de la población en casi veinte países.

Este artículo trata la presencia africana en las Américas no desde la perspectiva de la historiografía de la esclavitud — que es inmensa - sino como parte de la historia de las migraciones y formaciones socio-raciales en el nuevo mundo. La primera parte establece el origen, volumen, ritmo temporal y distribución geográfica de las llegadas empleando una base de datos que contiene información sobre unos 35.000 viajes de barcos negreros entre 1514 y 1866. Luego se analiza cómo esto determinó el impacto demográfico, desarrollo socioeconómico, presencia cultural africana, y taxonomías e identidades raciales en las regiones receptoras.

\section{ORÍGENES}

Como en el caso de otras migraciones supuestamente continentales, los orígenes geográficos de la africana eran bastante restringidos. El 40\% del tráfico se originaba en la costa de Angola, casi todo por los puertos de Benguela, Cabinda y sobretodo Luanda ${ }^{3}$. Los tres grupos principales - ovimbundu, ambundu y bakongo - compartían idiomas bantúes y con el tiempo los bautizaron en las Américas con el gentilicio genérico de bantú o congo. Con la lusitanización de la región muchos aprendieron algo de portugués, lo cual facilitó, como veremos luego, su adaptación en Brasil. La otra colonia portuguesa en el sur, Mozambique, fue la única fuente sustancial en la costa oriental. Esta surtió el 5\% del flujo transatlántico, en este caso casi todo concentrado en el siglo XIX y dirigido a Brasil, el principal importador de esclavos durante esa centuria.

El resto del flujo se originó en la costa occidental entre Senegal y Camerún. El golfo de Guinea por sí solo suministró casi la mitad de los esclavos exportados al nuevo mundo. Dentro de este y de sur a norte, el golfo de Biafra, sobre todo la zona al este de la desembocadura del rio Níger, proporcionó el 13\% del éxodo, la mayoría de etnia igbo (llamados carabalí en Hispanoamérica). El golfo de Benín justo al norte suministró cerca del 20\% del tráfico y uno de los grupos más influyentes en las Américas, los yorubas

2 LiviBacci, 2009: capítulos 5 y 8. Hemming, 1978.

3 Ferreira, X/20 (Niterói, 2006): 23-49. 
(llamados lucumí o nagos en las Antillas hispanas); y Ghana y la Costa de Marfil, proveyeron el 13\%, en su mayoría ewé, asante (llamados mina en el Caribe y Brasil) y otros hablantes de idiomas akan 4 . El resto, o el 5-7\% del total, se originaban más al norte, entre Cabo Palmas en Liberia y el río Senegal, con preponderancia étnica de mandingas, mendé y wólof ${ }^{5}$.

Casi dos terceras partes de los esclavos que cruzaron el Atlántico eran hombres. Pero, contrario a lo que comúnmente se asume, la proporción femenina (34\%) superaba a la de las inmigraciones europeas coloniales, que raramente llegaban al $25 \% 0^{6}$. Las tasas no variaban mucho por destino pero sí según el área de origen. Esto sugiere que los proveedores africanos determinaban la composición sexual del tráfico y varios estudios recientes iluminan cómo y porqué. La preferencia por la mano de obra masculina era bastante constante en las Américas, sobre todo en las economías azucareras que predominaban en la importación. Pero la demanda americana era mayor, casi consistentemente, que la oferta africana. Esto y el hecho de que el mercado doméstico de esclavos en Africa occidental era tan grande como el transatlántico, les daba una ventaja comparativa a los vendedores africanos. En las regiones donde el precio de las esclavas era superior por su doble valor como concubinas y productoras en la agricultura comercial, los mercaderes africanos vendían la mayoría de las mujeres en el mercado doméstico y exportaban a los hombres. En estos casos las preferencias de los importadores americanos y los exportadores africanos coincidían. Cuando no era así, la proporción masculina del tráfico transatlántico era menor a pesar de las preferencias de los compradores ${ }^{7}$.

\section{DEstinos}

Al igual que los orígenes, los destinos del tráfico eran más específicos y regionales que pan-continentales. El Cuadro 1 los muestra por colonias o países porque la información en las fuentes primarias y secundarias aparece así. Pero geografías naturales explican más que delimitaciones políticas en este caso. Los lugares de destino compartían topografía, clima y situación

4 Para los gentilicios usados en las Américas véase Ortiz, 1916: 25-40. Castellanos, XVII (Pittsburgh, 1987): 25-35.

5 Los orígenes regionales se calcularon usando las cifras en el «Trans-Atlantic Slave Trade Database» (véase la nota al Cuadro 1), pero Pétré-Grenouilleau, 2004: 25-35, contiene cuadros mostrando los puertos de salida para el siglo XVIII.

6 Eltis y Engerman, XXIII/2 (Massachusetts, 1992): 237-57.

7 Nwokeji, LVIII/1 (Williamsburg, 2001): 47-68. 
Cuadro 1. Destinos del tráfico de esclavos africanos, 1514-1866

\begin{tabular}{|c|c|c|}
\hline Destino & miles & $\%$ del total \\
\hline Brasil & 3.527 & $38,4 \%$ \\
\hline Caribe británico & 2.419 & $26,3 \%$ \\
\hline Jamaica & 1.083 & $11,8 \%$ \\
\hline Barbados & 452 & $4,9 \%$ \\
\hline San Cristóbal y Nieves & 176 & $1,9 \%$ \\
\hline Antigua & 142 & $1,5 \%$ \\
\hline Granada & 140 & $1,5 \%$ \\
\hline Dominica & 118 & $1,3 \%$ \\
\hline Guayana & 108 & $1,2 \%$ \\
\hline otros & 200 & $2,2 \%$ \\
\hline Caribe francés & 1.110 & $12,1 \%$ \\
\hline Saint-Domingue (Haití) & 794 & $8,6 \%$ \\
\hline Martinica & 204 & $2,2 \%$ \\
\hline Guadalupe & 69 & $0,8 \%$ \\
\hline otros & 43 & $0,5 \%$ \\
\hline Antillas hispanas & 844 & $9,2 \%$ \\
\hline Cuba & 801 & $8,7 \%$ \\
\hline Puerto Rico & 20 & $0,2 \%$ \\
\hline República Dominicana & 16 & $0,2 \%$ \\
\hline Caribe holandés y danés & 524 & $5,7 \%$ \\
\hline Guayana holandesa & 270 & $2,9 \%$ \\
\hline Antillas holandesas & 155 & $1,7 \%$ \\
\hline Antillas danesas & 99 & $1,1 \%$ \\
\hline Hispanoamérica continental & 391 & $4,3 \%$ \\
\hline Colombia, Panamá, Ecuador & 107 & $1,2 \%$ \\
\hline México y América Central & 106 & $1,2 \%$ \\
\hline Venezuela & 58 & $0,6 \%$ \\
\hline Perú & 46 & $0,5 \%$ \\
\hline Argentina, Uruguay, Paraguay, Bolivia, Chile & 43 & $0,5 \%$ \\
\hline $\begin{array}{l}\text { Estados Unidos } \\
\end{array}$ & 366 & $4,0 \%$ \\
\hline Total & 9.181 & $100,0 \%$ \\
\hline
\end{tabular}

Fuentes: compilado de información sobre casi 35.000 viajes de barcos negreros en el Trans-Atlantic Slave Database: www.slavevoyages.org. Los destinos específicos dentro de Hispanoamérica continental se calcularon en base de datos en Herbert Klein, 2010: 64-66. 
geográfica: tierras llanas tropicales o semi-tropicales en islas o en tierra firme pero raramente a más de cien kilómetros de la costa o de la ribera de ríos navegables. Elementos ecológicos, demográficos y estratégicos determinaron el emplazamiento: la existencia de tierras arcillosas donde se puede cultivar la caña de azúcar y otros frutos tropicales con demanda europea, la escasez o ausencia de mano de obra indígena y la cercanía a puertos, algo necesario antes del advenimiento del ferrocarril en los años 1830.

Dentro de estas restricciones ecológicas/geográficas, los destinos tomaron importancia en diferentes periodos y el peso relativo de la presencia africana varió entre ellos. Hasta la tercera década del siglo XVI, la mayor parte del tráfico se seguía dirigiendo no a las Américas sino a Madeira, Canarias, Cabo Verde, Portugal y Sevilla ${ }^{8}$. Los primeros esclavos en el nuevo mundo desembarcaron en la isla de Española. Pero las primeras llegadas masivas entraron por los puertos de Cartagena y Veracruz con destino a las zonas mineras del Perú y México. Durante la segunda mitad del siglo XVI y el primer cuarto del XVII estos dos virreinatos recibieron 193.000 esclavos, o el $91 \%$ del tráfico transatlántico total durante ese periodo según datos de los registros de veleros negreros compilados en el Trans-Atlantic Slave Trade Database (véase Cuadro 1 para la fuente). Pero estas cifras representan solo el $2 \%$ del tráfico transatlántico total, la población esclava en su momento cúspide alcanzó solo el $10 \%$ de la población en Perú y el $2 \%$ en México, y la trata declinó después de mediados del siglo XVII - al contrario del resto de las Américas donde el tráfico tomó dimensiones masivas después de esa fecha9.

El temprano desarrollo y declive del tráfico en las colonias españolas de tierra firme explica en gran parte la excepcionalmente alta proporción de personas libres entre la población afro-descendiente hacia finales del periodo colonial. Alrededor del 1790 esta proporción llegaba al 70\% en Hispanoamérica en comparación con el $40 \%$ en el norte y oeste de los Estados Unidos, el 29\% en Brasil y, más drásticamente, el $5 \%$ en el sur de los Estados Unidos y el Caribe francés y el 3\% en el Caribe británico ${ }^{10}$. Pero dentro de Hispanoamérica continental la proporción variaba dependiendo del dinamismo de la economía esclavista. En las zonas azucareras de la costa peruana, que crecieron durante finales del siglo XVIII, el 44\% de la población negra era esclava

8 Curtin, 1969: 115.

9 Para el tráfico de esclavos en Hispanoamérica durante la época, véase Newson y Minchin, 2007. Vila Vilar, 1977. Para Perú y México: Bowser, 1974. Aguirre, 2005. Bennett, 2003.

10 Bergad, 2007: 63, 114-117, 242. 
y en la costa de Venezuela, que pasaba por un boom en las exportaciones de cacao, la proporción esclava llegaba al $71 \%{ }^{11}$.

La influencia cultural africana en las colonias españolas de tierra firme, por lo tanto, fue menor que en el noreste de Brasil, las Antillas y el sur de los Estados Unidos y se concentró en las zonas tropicales costeras. En México se limita a algunas áreas en las costas de los estados de Veracruz y Guerrero. En la región andina se concentra, en Perú, entre Cañete y el Callao en la costa sur y Lambayeque y Piura en la costa norte; y en Ecuador en la provincia de Esmeraldas en la costa norte. Esta presencia fue, y sigue siendo, más importante que en México. La proporción afro-descendiente en las poblaciones actuales del Perú y Ecuador se estima entre el 3\% y el 8\%. La presencia negra es aún más notable en la costa pacífica de Colombia y Panamá, y en algunos tramos de la costa atlántica de Colombia (entre Cartagena y Santa Marta) y de Venezuela (entre Coro y Barlovento) ${ }^{12}$. La costa atlántica de América Central también contiene concentraciones de población negra pero la mayoría son descendientes de inmigrantes del Caribe anglófono que llegaron en el siglo XX, en el caso de Panamá y Costa Rica, y de estos y garífunas en el caso de Nicaragua y Honduras ${ }^{13}$.

La importación de esclavos en Brasil despuntó décadas después que en Perú y México — hacia principios de los años 1600 - pero duró más que en cualquier otro destino y de forma más masiva - aunque solo en cifras absolutas, no en relación a la dimensión del territorio ${ }^{14}$-. El tráfico descolló originalmente en Pernambuco durante la ocupación holandesa, 1630-1654, cuando recibió el 30\% del total transatlántico y el $82 \%$ de la parte que se dirigió a Brasili15. El número disminuyó drásticamente con la reconquista portuguesa y el declive económico de la región. Pero resurgió, con la economía y con aun mayor ímpetu, después de los años 1720, alcanzó su cúspide durante el primer cuarto del siglo XIX y continuó con fuerza hasta mediados de los años 1800. En total, casi medio millón de africanos entraron por el puerto de Recife. En términos relativos, sin embargo, Bahía se convirtió en el principal importador de mano de obra africana, recibiendo dos terceras partes de las entradas en Brasil durante el tercer cuarto del XVII y un $85 \%$

11 Elliott, 2006: 287.

12 Escalante, 1964: iii. Vidal Ortega, 2008: 161-64. Acosta Saignes, II/6 (Caracas, 1961): 13-61.

13 O’Reggio, 2006. Putnam, 2002. Chambers, 2010.

14 Para una recensión de la historiografía sobre la trata y la esclavitud africana en Brasil, véase Reis y Klein, 2011. Schwartz, 2011.

15 Para un excelente estudio de las relaciones entre las colonias portuguesas ocupadas por los holandeses en África (Sao Tome, Angola y el Congo) y Brasil, véase Ratelband, 2003. 
durante el último cuarto del siglo. Salvador, bautizada por algunos como la Roma africana del nuevo mundo, siguió siendo el principal punto de entrada durante los años 1700. El volumen aumentó vertiginosamente durante ese siglo, alcanzó su cúspide en el primer cuarto del siguiente y continuó con vigor hasta los años $1840^{16}$. En total, unos 1,4 millones de esclavos arribaron a Bahía.

Las cifras sobre entradas sin embargo esconden un importante desplazamiento del eje económico y demográfico brasileño. Gran parte de los esclavos que siguieron entrando por Salvador durante la primera mitad del siglo XVIII se re-exportaban a Minas Gerais que se encontraba en el apogeo de lo que el historiador inglés C. R. Boxer nominó, más con sentido doble que doble sentido, «the Golden age of Brazil», el auge de la economía minera que convirtió a la región en el productor de oro y diamantes mas importante del mundo ${ }^{17}$. Al contrario de lo que se creía, la esclavitud en Minas Gerais no disminuyó después que el oro se agotó durante la segunda mitad del siglo XVIII pues la región desarrolló una economía diversificada dirigida al mercado interno en vez de a la exportación. El censo nacional de 1872 muestra que el número de esclavos en la provincia se había duplicado en las cinco décadas previas y era el más alto en el país. Pero, como Laird Bergad mostró, esto no dependía de la importación sino de la capacidad de la población esclava de reproducirse biológicamente sin necesidad de constante reemplazamiento, uno de los pocos lugares donde esto sucedió fuera de los Estados Unidos ${ }^{18}$. En términos de la entrada transatlántica o re-exportación interna de esclavos, el siglo XIX presenció un constante movimiento hacia el sur atraído por la economía cafetera, primero en la provincia de Rio de Janeiro y por último en la de San Pablo ${ }^{19}$.

La trata en las Antillas británicas, francesas y holandesas despegó a mediados de los años 1600, o media centuria después que en Brasil, forjó un ciclo de azúcar y esclavitud que saltaba de isla a isla, alcanzó su ápice en el siglo XVIII y - al contrario de Brasil- casi desapareció después de la primera década del XIX. El proceso surgió en Barbados. Hacia 1645, esta colonia británica era una isla relativamente pobre con 800 esclavos y 20.000 ingleses, la mayoría sirvientes conchabados, que cultivaban tabaco, algodón e índigo. La introducción por los holandeses de la tecnología azucarera de Pernambuco transformó la situación. En las próximas décadas una isla de 23 por 34 kilómetros con una superficie seis veces más pequeña que Luxemburgo llegó a importar una cuarta parte del flujo transatlántico y engendrar más

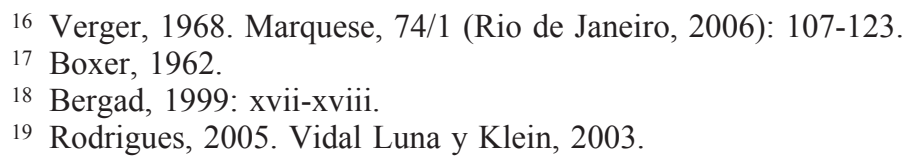


ganancias que todas las colonias británicas en Norteamérica en conjunto. La composición de la población pasó de $95 \%$ blanca a $90 \%$ negra y esclava en dos o tres generaciones. Los 440.000 esclavos que llegaron en el próximo siglo y medio sobrepasaron el número que entraron a todas las colonias españolas, con la excepción de Cuba, en cuatro siglos.

Otras islas seguirían los pasos de Barbados. Las siguientes, pocos años después, fueron las Antillas y Guayana holandesas que se unieron a la estampida hacia el azúcar y la esclavitud en el Caribe cuando los holandeses perdieron Brasil en 1654. En las próximas décadas estas colonias llegaron a recibir más de una tercera parte del tráfico transatlántico. Otras islas se incorporaron en las últimas dos o tres décadas del siglo. Las Antillas danesas recibieron 20.000 esclavos. Nieves, un islote británico en las Antillas menores cinco veces más pequeño que Barbados, importó 19.000, y Jamaica, 80.000, lo cual representó solo un preludio.

El siglo XVIII presenció la cresta de la ola esclavista y del dominio del Caribe inglés, francés y, en menor escala, holandés. Cinco millones y cuarto de esclavos, el 57\% del tráfico total, llegaron durante este siglo y casi dos terceras partes se dirigió a estas colonias. Jamaica con 920.000 y Haití con 790.000 sobresalieron en este infausto comercio. Pero no fueron los únicos. Barbados, aun relegado al tercer lugar, importó 312.000; la Guayana holandesa 230.000; Martinica 163.000; Antigua, San Cristóbal, y Granada más de 130.000 cada una; las Antillas danesas 64.000; San Vicente 53.000; Guadalupe 47.000; Tortola, Nieves, Monserrat y Tobago más de 12.000 , y la lista sigue.

La trata en las Antillas hispanas precedió y sucedió, la del resto del Caribe. Por un siglo y medio, entre 1492 y 1640, todos los esclavos en la región llegaron a las islas españolas, que entonces incluían a Jamaica y Trinidad, aunque los números eran escasos: unos 16.000, de los cuales 10.000 fueron a Santo Domingo. En 1546 esta colonia contenía 12.000 esclavos y 5.000 españoles. Algunos historiadores estiman que el número de esclavos alcanzó unos 25.000 hacia $1582^{20}$. Otros mantienen que cuatro años después una epidemia exterminó la mitad ${ }^{21}$. Varios otros factores frenaron la importación de africanos y la expansión de la esclavitud en los próximos siglos: el declive de una industria azucarera incapaz de competir con el resto del Caribe y Brasil, la falta de dinero, el cimarronaje y el desarrollo de una economía campesina basada en el ganado, tabaco y frutos que no se prestaba a un sistema de explotación esclavista ${ }^{22}$. En 1769 el número de esclavos no llegaba a nueve

20 Rodríguez Morel, XLIX (Sevilla, 1992): 89-117.

21 Moya Pons, 1998: 45, 50, 60.

22 Silié, XX (México, 1989): 163-170. Larrazábal Blanco, 1998. 
mil o el 14\% de la población de Santo Domingo mientras que en Saint-Domingue, al otro lado de la isla y con solo la mitad de la superficie, sobrepasaban el cuarto de millón y el 90\% de la población.

Puerto Rico se asemeja a Santo Domingo en la escasez del flujo pero no en su temporalidad pues el $90 \%$ arribó durante el último tercio de la historia del tráfico (1750-1850) en vez del primero. El número de esclavos ascendió de 5.037 en 1765 a 17.536 en 1812 y a un pico de 51.216 en 1846. Pero, a pesar del incremento, Puerto Rico continuó siendo una sociedad con esclavos más que una sociedad esclavista pues estas cifras representaban entre el 7\% y el $11 \%$ de la población, precisamente el antípoda de las sociedades esclavistas de las Américas donde del 3\% al 10\% de la población era libre. Aun si excluimos los blancos para evitar distorsiones en la comparación, durante el apogeo del tráfico negrero entre el $75 \%$ y el $85 \%$ de la población afrodescendiente de Puerto Rico era libre ${ }^{23}$.

Cuba constituye un caso particular, y a veces excepcional, en varios aspectos. Uno es lo tardío del proceso. E1 98\% de los esclavos llegaron después de 1780 y el $92 \%$ durante el siglo XIX. Otra peculiaridad es la alta concentración temporal del flujo. El $83 \%$ de los esclavos arribaron en menos de medio siglo (1816-1860). Este nivel de retardo y concentración es inusitado en el resto de las Américas. El único caso que se le asemeja un poco es la región de Rio de Janeiro. Como se muestra en el Cuadro 2, estas dos regiones dominaron el tráfico transatlántico durante sus últimas seis décadas, recibiendo entre el $58 \%$ y el $100 \%$ del flujo decenal entre 1810 y 1866 .

Cuadro 2. Proporción del trÁfico negrero transatlántico QUE ENTRÓ POR PUERTOS CUBANOS Y EN LA REGIÓN DE RIO DE JANEIRO, 1810-1866

\begin{tabular}{|c|c|c|c|}
\hline Décadas & $\begin{array}{c}\text { La Habana y otros puertos } \\
\text { cubanos }\end{array}$ & $\begin{array}{c}\text { Rio de Janeiro y otros puertos } \\
\text { del sureste de Brasil }\end{array}$ & Suma de los dos \\
\hline 1810 & $19 \%$ & $39 \%$ & $58 \%$ \\
\hline 1820 & $16 \%$ & $53 \%$ & $69 \%$ \\
\hline 1830 & $43 \%$ & $44 \%$ & $87 \%$ \\
\hline 1840 & $16 \%$ & $59 \%$ & $75 \%$ \\
\hline 1850 & $92 \%$ & $4 \%$ & $96 \%$ \\
\hline 1860 & $100 \%$ & $0 \%$ & $100 \%$ \\
\hline
\end{tabular}

Fuente: compilado de información sobre puerto de arribo en el Trans-Atlantic Slave Database: www.slavevoyages.org.

23 Cálculos basados en datos en Díaz Soler, 2005. Miller, 1922: 290. 
El volumen es igualmente excepcional. Más esclavos entraron en Cuba en tres décadas que en el resto de Hispanoamérica en conjunto en tres siglos. En esto Cuba comparte más con las colonias insulares británicas y francesas que con Hispanoamérica. Pero al contrario de Jamaica o Saint-Domingue, etc., en que más del $90 \%$ de la población era negra y esclava, el aluvión africano en Cuba llegó a una isla que por casi tres siglos había sido una colonia de asentamiento europeo, que siguió recibiendo inmigrantes españoles durante la época de la trata, y que después de la trata recibió un número de inmigrantes superior al total de los que entraron a través del tráfico negrero ${ }^{24}$.

En los Estados Unidos los primeros esclavos desembarcaron en la colonia de Virginia en 1619 pero la gran mayoría (el 96\%) llegaron durante el siglo XVIII y el primer cuarto del XIX. Antes de la independencia del país, unos 18.000 arribaron a las colonias del norte. Pero ese flujo cesó con la abolición de la esclavitud en los estados del norte después de 1776. En total, el $95 \%$ de los esclavos se dirigieron a las colonias o estados del sur y casi la mitad entró por el puerto de Charleston en Carolina del Sur. Este nivel de concentración regional obedece a razones ecológicas - los principales cultivos de las economías esclavistas, el algodón, tabaco, índigo y arroz no se dan, o se dan con mucha dificultad, en el norte- y superó el de Brasil, donde la mayoría de las importaciones entraron por las provincias del noreste y Rio de Janeiro, pero la esclavitud se extendió hasta Sao Paulo y el sur.

La particularidad más notable de la esclavitud en los Estados Unidos, sin embargo, no es su concentración regional sino la discrepancia entre el volumen del tráfico y el del stock. En 1860, cinco años antes de la abolición de la esclavitud, el país contenía casi dos tercios de los esclavos en las Américas pero había importado solamente el $4 \%$ de los esclavos que llegaron al nuevo mundo. Es cierto que para 1860 la esclavitud ya se había abolido en el Caribe no-hispano. Pero alrededor de 1780, en pleno apogeo de la esclavitud antillana, los Estados Unidos contenían casi un quinto de los esclavos en las Américas a pesar de haber importado hasta entonces solo el 5\% del tráfico. El que, como indican estas cifras, el stock de esclavos en el país fuera por lo menos cuatro veces más alto que el ingreso de esclavos manifiesta una situación poco común: la capacidad de la población esclava de reproducirse biológicamente de una manera sostenible. Esto refleja el clima menos insalubre de las regiones templadas como Maryland y Virginia, y de las regiones subtropicales más al sur en comparación con muchas de las costas e islas tropicales de las Américas que son mas húmedas y, relacionado a esto, la ausencia

24 Naranjo Orovio y García González, 1996. Moya, 2003. 
de plantaciones de caña de azúcar — la actividad con las tasas de mortalidad más altas.

\section{IMPACTO DEMOGRÁFICO}

Estas pautas en la inmigración forzada africana determinaron su impacto demográfico en las sociedades receptoras. Este impacto es más profundo y obvio en las Antillas británicas y francesas. Los esclavos africanos representaban la gran mayoría de la población de estas islas y los descendientes de estos siguen teniendo un peso demográfico enorme en ellas: Haití (95\% negro), Barbados (93\%), Jamaica (91\%), Martinica (90\%), las Bahamas y Curazao $(85 \%)$, Granada (82\%). Los pocos casos donde la proporción negra aparece más baja son el resultado de la menor intensidad de la esclavitud en el pasado de las islas y de un grado mayor de mestizaje (como en Aruba y San Martín), o del arribo de sirvientes conchabados indios asiáticos e indonesios durante la segunda mitad del siglo XIX y las primeras décadas del XX (como en Trinidad y Tobago, la Guayana inglesa y Surinam) ${ }^{25}$.

Fuera de las Antillas no españolas ningún país o región en las Américas tiene poblaciones negras — no simplemente de color — que sobrepasen el $80 \%$ de la población en general. Pero existen áreas más específicas y limitadas donde el peso relativo negro, o por lo menos afro-descendiente, sobrepasa o se acerca a ese nivel.

Los Estados Unidos tienen la población negra más numerosa del hemisferio, casi 40 millones, pero solo en un Estado (Mississippi) esta sobrepasa un tercio del total de habitantes y la cifra incluye un buen número de personas que en otros lugares se considerarían mulatos o pardos. Sin embargo, hay siete condados (todos en el sur), cuatro ciudades y cientos de pueblos donde los negros constituyen más de tres cuartas partes de la población. Aunque no existen datos específicos de manera consistente, proporciones similares se pueden encontrar en las siguientes zonas de Hispanoamérica continental: partes de los departamentos de Chocó, Nariño, Bolívar y el archipiélago de San Andrés y Providencia en Colombia; la provincia de Esmeralda y el Valle de Chota en Ecuador; Barlovento en Venezuela; la costa del departamento de Colón y la isla de Roatán en Honduras; y la costa de la provincia de Limón en Costa Rica.

En Brasil la población negra es tres veces más pequeña que la de los Estados Unidos pero la población de color en general duplica la norteamericana.

25 West-Durán, 2003: 141-154. 
Esto en parte refleja la diferencia entre una taxonomía racial dual, basada en la descendencia y particularmente exclusivista, y otra que admite categorías intermedias, se basa en la apariencia fenotípica, y acepta como blancos a personas con alguna ascendencia africana. Pero también refleja diferencias en el nivel de mestizaje biológico. Estudios genéticos recientes indican que la proporción de ascendencia europea en la población afro-descendente brasileña es tres veces más alta que en la norteamericana ${ }^{26}$. De cualquier manera, el peso demográfico negro y mulato (preto y pardo) no llega a los niveles del Caribe no-hispano aun en sus mayores concentraciones: la zona metropolitana de Salvador de Bahía ( $29 \%$ negro y $54 \%$ mulato) y con menor contingente negro, otras regiones nordestinas; las zonas costeras de la provincia de Rio de Janeiro (13\% y 34\%); y la zona sur de Minas Gerais (12\% y 47\%)

Las Antillas españolas también se distinguen del resto de las islas caribeñas en su proporción negra más baja y más concentrada geográficamente. En Cuba la proporción de los habitantes que se declaran negro en los censos desde 1899 varía entre el 10 y el 15\%; en Puerto Rico entre el 7 y el 12; y en la República Dominicana entre el 11 y el 25. En cuanto a su distribución geográfica, el censo cubano de 1907, que contiene información sobre la composición racial a nivel local, muestra que en solo 9 de los 101 municipios de la isla los residentes de color (término que incluía mulatos y chinos) constituían más de la mitad de la población ${ }^{28}$. En Puerto Rico, la población negra supera un tercio del total en solo uno de los 78 municipios de la isla: Loíza, con el 64\%. En la República Dominicana la presencia relativa de la población negra es más alta en las zonas azucareras de la costa sur, el resultado en gran parte de migraciones haitianas desde los años $1920^{29}$.

\section{CONSECUENCIAS SOCIOECONÓMiCAS}

Las diferencias regionales en el volumen del tráfico de esclavos y el tamaño relativo de las poblaciones de color fraguaron en gran parte las estructuras socioeconómicas futuras de las sociedades receptoras. Durante el auge

26 Pena et al., VI/2 (San Francisco y Cambridge, 2011): http://www.plosone.org/article/ info:doi/10.1371/journal.pone.0017063. Kayser et al., XIII (Nueva York, 2003): 624-634.

27 IBGE, 2007.

${ }_{28}$ Los nueve municipios donde la población de color sobrepasaba la mitad de la población total en 1907 eran Jovellanos en la provincia de Matanzas y, en orden descendiente, el Cobre, Alto Songo, San Luis, Guantánamo, Santiago, Palma Soriano, Baracoa y Caney, todos en el sureste de la provincia de Oriente.

29 Matibag, 2003: 132-136. 
de la esclavitud, las economías de plantación se encontraban entre las más prósperas del hemisferio. Barbados sobrepasaba las colonias británicas de Norteamérica en productividad y riqueza. Entre las últimas, las del sur superaban las del norte. En Brasil ocurría lo inverso en términos geográficos pero tenía el mismo significado en términos económicos. La pequeña Saint-Domingue generaba más peculio para los franceses que las enormes extensiones de Quebec y Luisiana. Pero esta eficiencia y abundancia se basaban en un nivel de explotación de la mano de obra y de una verticalidad en la estructura social que no eran sostenibles a largo plazo y dejaron cimientos frágiles para la construcción de estados nacionales y economías de mercado.

Consecuentemente, la relación se fue invirtiendo desde mediados de los 1800 y ya para principios del siguiente siglo la proporción negra en la población se había convertido en un fuerte indicador de pobreza en vez de riqueza. Hoy día el PIB per cápita en la República Dominicana es casi ocho veces más alto que en Haití, una brecha que duplica la que existe entre Alemania y la República Dominicana, y dentro del país las provincias con mayor concentración de población negra en la frontera y el sur muestran las tasas de pobreza más altas ${ }^{30}$. El extremo oriental de Cuba se convirtió en la región más pobre de la isla y medio siglo de políticas socialistas no han cambiado su situación relativa. En Colombia, los municipios con mayor concentración de población negra en los departamentos del Chocó, Nariño y Bolívar muestran los niveles más altos de indigencia ${ }^{31}$. Los quince condados norteamericanos con los porcentajes de población negra más altos se encuentran todos entre el 3\% más pobre de los 3.194 condados del país. Los índices de pobreza extrema en las provincias del noreste de Brasil son entre 5 y 16 veces más altos que en las provincias del sur.

La historia no es una condena inescapable y el buen gobierno puede alterar destinos. Esto ha ocurrido, por ejemplo, en Barbados —una sociedad con un fuerte pasado de esclavitud que hoy se encuentra entre los 47 países con índices de desarrollo humano más altos del mundo-. Pero la correlación entre un pasado de riqueza esclavista y un presente de subdesarrollo socioeconómico es tan contundente como explícita a niveles hemisféricos, nacionales y locales.

30 Cálculo basado en información en la sección «perfiles provinciales» de la Oficina Nacional de Estadísticas (de la República Dominicana), www.one.gob.do.

31 Pérez, 2005. 
Presencia CUltural AFricAna

La duración o ritmo temporal del tráfico de esclavos también afectó la importancia relativa de la presencia cultural africana, no simplemente negra. Fuera de Cuba y Brasil, los sitios con altos niveles de preservación cultural africana son relativamente pequeños y aislados. San Basilio de Palenque, un pueblo $50 \mathrm{~km}$ al sureste de Cartagena de Indias, fue - como lo indica su nombre - fundado por cimarrones. Cerca de la mitad de sus 3.500 habitantes, sobre todo los ancianos, todavía hablan palenquero, que incorpora vocabulario bantú y es el único patois español en las Américas ${ }^{32}$. La UNESCO designó el lugar patrimonio cultural de la humanidad por su excepcional preservación de elementos africanos. Otro caso de preservación cultural africana es el de los garífunas, descendientes de esclavos provenientes de la costa nigeriana que naufragaron en la isla de San Vicente, se mezclaron con indios caribes, fueron deportados por los británicos a la isla de Roatán en 1796 y con el tiempo se establecieron en el sur de Belice, Livingston y sus alrededores en la costa guatemalteca, y varios pueblos en la costa hondureña $\mathrm{y}$, en menor grado, nicaragüense ${ }^{33}$. Con una historia menos peripatética, los Gullah, un grupo de negros norteamericanos asentados en algunos pequeños pueblos rurales y pesqueros e islas en la costa de Sur Carolina y Georgia, han preservado un lenguaje criollo, cuyo vocabulario proviene en parte de Sierra Leona, y elementos africanos en la cocina.

La presencia cultural africana es más notable en Brasil y Cuba porque estos dos destinos recibieron la inmensa mayoría del flujo africano durante las últimas cinco décadas de la trata esclavista. Esto conservó prácticas culturales específicas a etnias africanas relacionadas a la religión, lenguaje, música y sociabilidad a un nivel poco común en el resto del hemisferio, aun en las Antillas anglófonas y francófonas con mayorías negras en la población. Lo más parecido a una religión africana en estas últimas es el vudú haitiano. Pero a pesar de sus orígenes ewé y fon este es un producto sincrético y criollo en comparación con prácticas religiosas como los «tambores» de Mina y Nago en Brasil con sus claras conexiones asante y yoruba, o el palo Mayombe y las reglas Kimbisa y Brillumba en Cuba con sus referencias a regiones específicas cerca de la desembocadura del rio Congo y su uso ritual de la lengua kikongo, y no simplemente una mezcla de lenguas bantú, como ha demostrado un estudio lexicográfico reciente ${ }^{34}$.

\footnotetext{
32 Granda, XXIX/3 (Madrid, 1973): 435-439.

33 Gargallo, XIV (México, 2000): 89-107.

34 Guerra y Schwegler, 2005: 16, 45, 81-82.
} 
Esto refleja el hecho de que en el siglo XIX Brasil y Cuba eran no solamente países con alta población negra sino también sociedades de inmigración africana. Como en otras sociedades de aluvión, la asimilación de los inmigrantes cubría un espectro de aculturación. La mayoría de los que llevaban dos o tres generaciones en el país se integraban a la cultura local o a sus versiones afro-criollas. Pero los recién llegados y muchos de sus descendientes inmediatos se agrupaban por orígenes etno-regionales en una manera parecida a lo que ocurría con grupos nacionales europeos o grupos etno-regionales británicos, españoles o italianos. Las cofradías o los cabildos de «nación» no se distinguen mucho de las sociedades de socorros mutuos gallegas, irlandesas o sicilianas. Juntaban a miembros del mismo origen regional que contribuían a un fondo común para el sostén de la asociación y ayuda mutua, y socializaban en reuniones informales, bailes y verbenas.

La historia del abakuá, una sociedad secreta fundada en La Habana en 1836, encarna los procesos de llegada, adaptación, preservación cultural y asimilación comúnmente asociados con los inmigrantes libres. Su combinación de lealtades localista, ayuda mutua, actividades ilícitas y hermetismo evoca otras asociaciones de inmigrantes como las tríadas de los chinos y los «county societies» de los irlandeses. Sus fundadores, como los de muchas otras instituciones de inmigrantes, se inspiraron en modelos del lugar de origen (en este caso el Ekpé, «leopardo» en ibibio, una sociedad secreta en la costa calabar de Nigeria) y de la sociedad receptora (en este caso, cofradías). También se dividieron en tres subgrupos por origen comunal - efík, uruan y efó- de la misma manera que los gallegos, sus vecinos en La Habana, formaban sociedades parroquiales, los italianos asociaciones de paese y los judíos landsmanshaftn. Sin embargo, los fundadores no eran esclavos recién llegados sino «negros curros», por lo general libres, urbanos, hispanizados y con mayor familiaridad de los hábitos locales —el prototipo de líder étnico en grupos inmigrantes-. Con el tiempo los subgrupos localistas se fueron consolidando y la membresía se fue abriendo de manera incremental: a la etnia igbo en general, a otros africanos del golfo de Guinea, a negros criollos y eventualmente a mulatos, chinos y blancos —otro proceso común en la evolución de las asociaciones voluntarias de inmigrantes ${ }^{35}$.

Este proceso de consolidación y apertura generó otra característica habitual en las asociaciones de inmigrantes: la tensión entre el deseo de crecer y los reclamos de autenticidad. Para 1880 ya existían 88 logias abakuá dentro de La Habana vieja. En 1940 había 130 en el país y los ñáñigos, el nombre co-

35 Miller, 2009: 24, 33-40. 
mún de los miembros de la asociación, ejercitaban una gran influencia en los sindicatos portuarios de la isla. Hoy quedan 114 grupos con unos 20.000 miembros. Pero desde muy temprano la expansión generó oposición entre aquellos que no querían admitir negros criollos y otros grupos y hasta el día de hoy una de las ramas del abakuá admite solamente negros y emplea un discurso de exclusivismo ifik (un subgrupo carabalí) para racionalizar la práctica $^{36}$.

Las diferentes experiencias étnicas también influenciaron las estrategias de adaptación de los inmigrantes y la formación de estereotipos intra-africanos. Todas las rebeliones de esclavos en Bahía durante la primera mitad del siglo XIX para las que existen evidencias se componían básicamente de malés. El término, que apareció en Brasil para esa época, se refería a varios grupos musulmanes, la mayoría yorubas, pero se convirtió casi en sinónimo de hausa porque este grupo del norte de Nigeria era, y sigue siendo, el más ferviente y ortodoxo en su islamismo y el más visible en el liderazgo. Por otra parte, los esclavos congo, originales de Angola, que constituían casi la mitad de la población africana en Bahía, se mantuvieron completamente al margen de las rebeliones ${ }^{37}$.

Lo malés y los congo desarrollaron narrativas para explicar el contraste. Los primeros se autodefinían como dignos y valientes y tildaban a los congo de sumisos y cobardes. Los últimos se consideraban sensatos e ingeniosos y tachaban a los malés de iracundos e inadaptables. Pero, al igual que otros grupos inmigrantes, ambos simplemente usaban el capital sociocultural a su disposición en sus estrategias de adaptación. Los congo venían de colonias portuguesas y llegaban semi-lusitanizados y llevaban más tiempo en Brasil. Su mayor familiaridad con los hábitos y códigos culturales de la sociedad receptora y sus más densas y extensas redes sociales les permitía mejorar su situación sin tener que acudir a la resistencia abierta. Por ende gozaban de mejores posiciones dentro del sistema esclavista (empleos domésticos, artesanos, capataces, buhoneros y mayores tasas de manumisión). Por el otro lado, para los malés - recién llegados, sin previa familiaridad con la cultura lusobrasileña, separados por lenguaje y religión, y con pocas conexiones locales fuera de sus propios grupos - la resistencia frontal era la única estrategia viable.

Los mismos estereotipos étnicos existían en Cuba, manifestando la naturaleza diaspórica de estas construcciones culturales. Esteban Montejo en su famosa biografía de un cimarrón señala que «el lucumí (yoruba) y el congo

\footnotetext{
36 Routon, 2006: 33-68. Sosa, 1982: 119-126, 138.

37 Reis, 1993: 43, 49, 97-98, 152-58.
} 
no se llevaban» y describe a los primeros como «los más rebeldes y valentones» y a los últimos como «más bien cobardones», añadiendo que «hay una jutía que le dicen conga; muy cobardona ella» ${ }^{38}$.

Brasil y Cuba también muestran otros dos elementos comunes en las formaciones de estereotipos étnicos en sociedades de aluvión: la tendencia a definir los rasgos físicos y fenotípicos de los inmigrantes y a establecer jerarquías culturales entre ellos. La tendencia cruzaba clases sociales y razas. Para el insigne antropólogo brasileño Gilberto Freyre, los sudaneses (entre los que incluía a los mandingas, hausas y yorubas) eran «el pueblo más alto del mundo» y los del sur de África, chatos, anchos y culones ${ }^{39}$. Montejo, esclavo criollo hijo de padre «lucumí de Oyó», insistía que «cada negro tenía un físico distinto»: los mandinga eran «los más grandes» y «mas coloraúzcos»; los musongo (sonyo, un grupo bantú) «más anaranjados»; los gangas «bajitos y de cara pecosa», el congo «bajito y trabado» ${ }^{40}$. Un capitán de barco negrero coincidía sobre la estatura de los congo, a quienes consideraba «un pueblo diminuto, comparados con otros nativos de África» ${ }^{41}$. En efecto, las observaciones sobre la estatura coincidían mucho más que aquellas sobre pigmentación. Con regularidad los grupos que se originaban en el norte, entre la bahía de Benín y el río Senegal, se describían como más altos y físicamente superiores a los que venían de Mozambique, Angola y el delta del río Congo; y los datos que han sobrevivido sobre mediciones de esclavos concuerdan con las observaciones ${ }^{42}$.

Las comparaciones sobre estatura física tienden a encajar con las jerarquías culturales. Aquí también las observaciones no se limitan a ninguna clase social, nacionalidad o raza. Esclavos y amos, negros, blancos y mulatos, visitantes y residentes, legos y letrados coinciden en sus descripciones de los grupos del norte como más adelantados y menos supersticiosos. Montero describe a los congo como asesinos y brujos y a los lucumís como moderados, cultos y «ligados a los santos y Dios» ${ }^{43}$. A los grupos del norte que el capitán de barco mencionado arriba describe como altos, esbeltos y fornidos (hausas, yorubas, igbos, fantis, ashantis) también les atribuye pujanza, sobriedad, pericia y hasta republicanismo; mientras que interpreta la baja estatura de los congo y otros grupos bantú como un resultado de su indolencia (pues, según

\footnotetext{
38 Barnet, 1977: 15, 67.

39 Freyre, 1986: 319.

40 Barnet, 1977: 16, 67.

41 Adams, 1823: 159-160.

42 Warner-Lewis, 2003: 23-26.

43 Barnet, 1977: 14-15, 67.
} 
el capitán, el medio ambiente era más salubre y fértil que al norte del ecuador) y una causa de su falta de virilidad y afeminación ${ }^{44}$. Nina Rodrigues (18621906), uno de los principales intelectuales de su época, dedicó su influyente estudio de los afro-brasileños a demostrar no que los «sudaneses» eran superiores a los bantú, pues eso ya se tomaba por sentado, sino a refutar el argumento que la mayoría de los esclavos en Brasil provenían de esos grupos bantú inferiores y a probar y enfatizar la presencia de los supuestos grupos superiores. Esta idealización y énfasis de la presencia sudanesa/yoruba se convirtió en un leitmotiv de la antropología nacionalista en Brasil, incluyendo la obra de Freyre.

La analogía de esta dicotomía de norte-alto-superior y sur-bajo-inferior con el caso de la inmigración europea es notable. Los mismos intelectuales brasileños que minimizaban la presencia bantú y resaltaban la yoruba reproducían el esquema con los colonizadores lusitanos minimizando la presencia del Portugal austral «pardo o negroide y plebeyo» y enfatizando la del Portugal «nórdico, rubio y aristocrático» ${ }^{45}$. El prominente historiador Oliveria Vianna, para dar solo un ejemplo, afirmaba en su clásica obra Evolugao dopovo brasileiro (1923, páginas 12530), que los colonizadores del país eran un pueblo nórdico descendiente de los invasores celtas y visigodos de la península ibérica. La analogía persiste aun sin las referencias en Oliveria Vianna a las teorías raciales de Chamberlain y de Gobineau. La dicotomía en las actitudes hacia los africanos semeja en general la mayor reputación en las Américas de los inmigrantes del norte de Europa en comparación a los del sur, de los italianos del norte en comparación con los del mezzogiorno, o los vascos y catalanes en comparación a los andaluces.

Otro elemento en la presencia africana que semeja otras experiencias migratorias es la persistencia de los lazos entre origen y destino y sus usos simbólicos y políticos. La invitación en 1987 por parte de la Asociación Cultural Yoruba de Cuba a Sijawade Olobuse II, el «rey de reyes» de los yorubas y Oni, o babalaó (líder espiritual) de la ciudad sagrada nigeriana de Ifé, ilustra este proceso. Rumores en la isla mantenían que la profecía oracular de los babalaos cubanos había vaticinado que Fidel Castro moriría ese año a no ser que el Oni de Ifé besara el suelo cubano. Ese mismo año la asociación yoruba y el máximo líder cubano invitaron al Oni, quien de hecho besó la pista a su llegada. Homenajeado por las autoridades cubanas y el propio Castro - de manera no muy distinta de como los políticos en sistemas democráticos aga-

\footnotetext{
44 Adams, 1823: 14-15, 37-38, 132-33, 160-63.

45 Freyre, 1986: 199-205, 221-26.
} 
sajan a visitantes ilustres para ganarse el voto inmigrante o étnico- el Oni exhortó a los babalaos cubanos a que apoyaran al régimen socialista.

La secuela de eventos a la visita del Oni se podría haber dado fácilmente en la colectividad irlandesa de Boston o la gallega de La Habana. El Oni felicitó a sus paisanos en Cuba por haber mantenido la cultura yoruba viva por tanto tiempo, estimando que el $80 \%$ de la religión era como en la madre patria y declarando a Cuba subsede de la ciudad sagrada de Ifé. Encuentros y conferencias culturales, financiados por recursos públicos, prosiguieron la vistita y con estas, disputas entre diferentes asociaciones y líderes étnicos sobre inclusión, recursos y autenticidad. Algunos se sentían excluidos del proceso, lo tachaban de político y clientelista. Calificaban al Oni de megalómano, con su cortejo y cuarenta esposas, y de albergar intereses económicos más que espirituales, y se sintieron insultados por el estimado del « $80 \% »$ pues cuestionaba la integridad y pureza de la religión. Otros participaban en los encuentros transatlánticos con entusiasmo y comenzaron un programa de «yorubanización» de la santería con el propósito de eliminar elementos sincréticos ${ }^{46}$.

Por último, la añoranza de volver y algunos casos de regreso físico constituyen otras analogías a la inmigración libre. Lo primero adquirió tanta relevancia y ardor que los esclavos, sobre todo los recién llegados, se suicidaban a menudo con la esperanza de que sus almas volaran a África, como cuenta con una inocencia desbastadora el cimarrón Esteban Montejo en sus relatos autobiográficos y examina Louis Pérez en su libro sobre el suicidio en Cuba ${ }^{47}$. El retorno físico tomó varias formas. Unos 14.000 negros y mulatos norteamericanos emigraron a Liberia durante el siglo XIX bajo los auspicios de la American Colonization Society, una agrupación fundada por filántropos blancos con el propósito de facilitar el «retorno» de ex-esclavos. Otras organizaciones parecidas patrocinaron la emigración a Sierra Leona de negros del Caribe inglés. Los emigrantes acabaron convirtiéndose en un grupo colonial y dominante ${ }^{48}$. Algunos emigraron por su cuenta y, sobre todo desde Brasil, muchos en realidad retornaron, formando colectividades en el sur de Nigeria, Mali, Dahomey y otras regiones de África occidental, que aun hoy retienen memorias de origen e identidades distintivas ${ }^{49}$.

\footnotetext{
46 Routon, 2006: 223-25.

47 Pérez, 2005: 41-50.

48 Jenkins, 1975.

49 Matory, XLI/1 (Cambridge, 1999): 72-103.
} 
TAXONOMÍAS E IDENTIDADES RACIALES

La duración del tráfico y/o de la esclavitud y el tamaño relativo de la población de color también produjeron diferencias regionales en las categorías, relaciones e identidades raciales. En un extremo se encuentran lugares como Santo Domingo, Aruba y San Martín donde el tráfico fue menos intenso y menos prolongado y la esclavitud menos importante y menos duradera - por lo menos de facto - . Esto generó altos niveles de manumisión, mestizaje, mayorías libres en la población de color y unas culturas y sociedades mulatas donde la conciencia de color existe pero las categorías raciales son difusas y las identidades raciales débiles. En el caso de Santo Domingo esto coincide con un grado importante de prejuicio anti-negro y anti-africano que se dirige normalmente contra Haití o los inmigrantes haitianos en la República Dominicana en vez de manifestarse internamente ${ }^{50}$.

El otro extremo lo ocupan regiones donde la esclavitud duró más y la población no-negra era más numerosa. El ejemplo axiomático es el sur de los Estados Unidos donde los blancos, la mayoría sirvientes conchabados o sus descendientes, constituían más de la mitad de la población y donde la esclavitud duró hasta 1865. La paridad demográfica fomentó la dualidad y la separación. El alto número de blancos pobres o de modestos recursos restringió espacios en el mercado de trabajo libre para los negros y, por ende, oportunidades de manumisión. Todo esto, más la presión política de los artesanos y pequeños agricultores blancos, fomentó la construcción de una dicotomía racial rígida donde la línea divisoria era menos permeable que en otras sociedades esclavistas y post-esclavistas y bloqueaba el acceso al estatus de blanco aun a aquellos cuya ascendencia era mayormente europea ${ }^{51}$.

Esta dualidad continuó fuera del sur del país durante el éxodo de 7,7 millones de negros hacia las ciudades y zonas industriales del norte durante el siglo $\mathrm{XX}^{52}$. La dualidad se manifiesta geográficamente en niveles de segregación residencial negra muchos más altos que el de los inmigrantes europeos, aun los más segregados, como los judíos e italianos. La separación de facto en escuelas, iglesias, asociaciones y otras instituciones continuaron la dualidad en otros espacios de sociabilidad. Las categorías raciales preservaron la rigidez que habían desarrollado en el sur. Varios historiadores argumentan que la integración y asimilación de los inmigrantes europeos en buena parte se basó en la exclusión material y simbólica de los migrantes negros.

\footnotetext{
50 Matibag, 2003.

51 Daniel, 2006: 87-118.

52 Cálculo sobre cifras en Gregory, 2005: 330.
} 
Los inmigrantes europeos más recientes, discriminados y excluidos del poder a nivel nacional -irlandeses, italianos, judíos y otros grupos del sur y el este de Europa- se la agenciaron para dominar los estratos de poder más bajos - la política barrial, los empleos municipales y los sindicatos- y excluir a los migrantes afroamericanos. Su acceso a la clase trabajadora acomodada o media y al estatus cultural de americanos y racial de blancos se sustentó en la exclusión de los afroamericanos a un estatus de alteridad casi permanente. Grupos que habían sido considerados por la sociedad dominante como inferiores racialmente accedieron a la blancura en gran parte a fuerza de diferenciarse de los negros ${ }^{53}$.

Un patrón análogo, aunque menos excluyente, aparece en otras regiones con coyunturas históricas parecidas. Cuba y Sao Paulo comparten con el sur de los Estados Unidos una esclavitud masiva y duradera y (con la excepción de Matanzas y el extremo este de Cuba) una mayoría blanca (por lo menos antes del éxodo postrevolucionario). Al contrario del caso norteamericano, las taxonomías raciales de estas dos regiones nunca se definieron legalmente y admitían informalmente la existencia de categorías intermedias. Pero también contenían identidades raciales más fuertes y duales que en el resto de América Latina y una categoría, «de color», que incluía a negros y mulatos y proveía un mecanismo de exclusión parecido al concepto de «colored» en el sur de los Estados Unidos.

Las ciudades y zonas más ricas del oeste de Cuba y el sur de Brasil también recibieron migraciones internas negras durante el siglo XX. Como en el caso de los Estados Unidos, los inmigrantes europeos trataron de controlar el poder local y excluir a los migrantes negros. El discurso nacional de democracia racial obstaculizó esos esfuerzos pero no del todo. Los inmigrantes blancos y sus descendientes controlaban gran parte del comercio y la industria, las fuentes de empleo (lo que les permitía contratar a sus compatriotas) y los sindicatos $^{54}$. Las identidades raciales eran relativamente fuertes con asociaciones sociales, cívicas y aun políticas, blancas y negras, en algunos casos - como los grupos inspirados por el separatista negro jamaiquino Marcus Garvey - abierta y explícitamente, en otros simplemente en la práctica. En gran medida, estos regímenes raciales se asemejan más al de los del norte de los Estados Unidos que al del resto de Latinoamérica y el parecido se ha incrementado en las últimas décadas con la convergencia hacia un sistema informal que fusiona la discriminación racial, clasista y cultural ${ }^{55}$.

\footnotetext{
53 Moya, XXXV/3 (Varsovia, 2009): 101-102.

54 Andrews, 1991: 62-68.

55 Daniel, 2006.
} 
En los otros casos de equilibrio y dualidad el otro elemento no es europeo. En Trinidad y Tobago la población de origen indio asiático constituye el 40\% del total y la de origen africano el 58\%. En la Guayana inglesa las proporciones son el 44\% y 47\%. En Surinam el 37\% de la población es de origen indio asiático, el $15 \%$ original de Java y un $52 \%$ afro-descendiente. Aunque los asiáticos llegaron como sirvientes conchabados -al igual que el $75 \%$ de los europeos en el sur de los Estados Unidos- con el tiempo se fueron formando en un grupo comerciante. La segregación ocupacional que esto genera, el balance demográfico entre los dos grupos, la asociación de la identidad étnica y partidaria (con partidos políticos que representan los intereses de los grupos étnicos) y altos niveles de endogamia han forjado sociedades segmentadas en vez de mestizas.

Esta situación de relativa separación donde coexisten dos o tres grupos en equilibrio sin que ninguna de sus culturas se imponga como hegemónica es común en gran parte del mundo pero excepcional en las Américas. Y a su vez ha facilitado otro arreglo nacional excepcional en el nuevo mundo: países mosaicos donde, además de los grupos principales, otros grupos minoritarios (chinos, libaneses, brasileños, hispanoamericanos y descendientes de varias nacionalidades europeas) coexisten sin desaparecer en un crisol de etnias en unas pocas generaciones.

Ya sea en combinación con europeos o asiáticos, la presencia africana en las Américas ha contribuido enormemente a la formación social de gran parte del hemisferio. La esclavitud es un elemento central en esta presencia. Esta explica la distribución geográfica de la población negra, la transposición de exuberancia económica a subdesarrollo en las regiones con mayor concentración de esa población, y en cierta medida — aunque esto es mas debatible - la continua discriminación durante los siglos XX y XXI aun en regiones donde nunca existió la esclavitud pero que recibieron migraciones negras internas. Pero la otra parte de este proceso es una historia de inmigración que incluye continuidades culturales, estrategias de adaptación, formas de sociabilidad, desarrollo de identidades colectivas, procesos de aculturación y asimilación, formación de estereotipos étnicos, simbología y política de colectividades y añoranzas de retorno. El movimiento fue forzado y se asemeja más al comercio que a la migración libre. Pero el resto del proceso incluyó un sorprendente grado de libre albedrío, un testamento de la fuerza de la voluntad personal y colectiva aun dentro de los regímenes de control más opresivos. 


\section{BIBLIOGRAFÍA}

Acosta Saignes, Miguel, «La trata de esclavos en Venezuela», Revista de Historia, II/6 (Caracas, 1961): 13-61.

Aguirre, Carlos, Breve historia de la esclavitud en el Perú, Lima, Fondo Editorial del Congreso del Perú, 2005.

Andrews, George Reid, Blacks \& Whites in Sao Paulo, Brazil, 1888-1988, Madison, University of Wisconsin Press, 1991.

Bennett, Herman L., Africans in Colonial Mexico: Absolutism, Christianity, and AfroCreole Consciousness, 1570-1640, Bloomington, Indiana University Press, 2003.

Bergad, Laird, Slavery and the Demographic and Economic History of Minas Gerais, Brazil, 1720-1888, Cambridge, Cambridge University Press, 1999.

Bergad, Laird, The Comparative Histories of Slavery in Brazil, Cuba, and the United States, Nueva York, Cambridge University Press, 2007.

Bowser, Frederick, The African slave in colonial Peru, 1524-1650, Stanford, Stanford University Press, 1974.

Boxer, C. R., The Golden Age of Brazil, 1695-1750, Berkeley, University of California Press, 1962.

Castellanos, Jorge y Castellanos, Isabel, «The Geographic, Ethnologic, and Linguistic Roots of Cuban Blacks», Cuban Studies, XVII (Pittsburgh, 1987): 25-35.

Chambers, Glenn A., Race, Nation, and West Indian Immigration to Honduras, 18901940, Baton Rouge, Louisiana State University Press, 2010.

Curtin, Philip D., The Atlantic Slave Trade: A Census, Madison, University of Wisconsin Press, 1969.

Daniel, Reginald, Race and Multiraciality in Brazil and the United States: Converging Paths?, University Park, Pennsylvania State University, 2006.

Díaz Soler, Luis M., Historia de la esclavitud negra en Puerto Rico, San Juan, Universidad de Puerto Rico, 2005 [original 1953].

Elliott, John H., Empires of the Atlantic World: Britain and Spain in America, 14921830, New Haven, Yale University Press, 2006.

Eltis, David y Engerman, Stanley, «Was the Slave Trade Dominated by Men?», Journal of Interdisciplinary History, XXIII/2 (Massachusetts, 1992): 237-57.

Eltis, David y Richardson, David, Extending the Frontiers: Essays on the New Transatlantic Slave Trade Database, New Haven, Yale University Press, 2008.

Escalante, Aquiles, El negro en Colombia, Bogotá, Universidad Nacional, 1964.

Ferreira, Roquinaldo, «Biografía, mobilidade e cultura atlántica: a micro-escala do tráfico de escravos em Benguela, sáculos XVIII-XIX», Tempo, X/20 (Niterói, 2006): 23-49. 
Ferreira, Roquinaldo, Cross-Cultural Exchange in the Atlantic World: Angola and Brazil During the Era of the Slave Trade, Cambridge, Cambridge University Press, 2012.

Fuente, Alejandro de la, «Two Dangers, one Solution: Immigration, Race, and Labor in Cuba, 1900-1930», International Labor and Working-Class History, LI (Cambridge, 1997): 30-49.

Fuentes Guerra, Jesús y Schwegler, Armin, Lengua y ritos del Palo Monte Mayombe: Dioses cubanos y sus fuentes africanas, Madrid, Iberoamericana, 2005.

Gargallo, Francesca, «Los garífuna de Centroamérica: Reubicación, sobrevivencia y nacionalidad de un pueblo afroindoamericano», Política y cultura, XIV (México, 2000): 89-107.

Granda, Germán de, «Algunas observaciones morfológicas y etimológicas sobre vocabulario de origen bantú en el habla criolla de San Basilio de Palenque», Revista de dialectología y tradiciones populares, XXIX/3 (Madrid, 1973): 435-441.

Gregory, James N., The Southern Diaspora: How the Great Migrations of Black and White Southerners transformed America, Chapel Hill, University of North Carolina Press, 2005.

Hemming, John, Red Gold: The Destruction of the Brazilian Indians, 1500-1760, Cambridge, Harvard University Press, 1978.

IBGE, Instituto Brasileiro de Geografía e Estatística, Pesquisa Nacional por Amostra de Domicilios 2007. www.ibge.gov.br/home/estatistica/populacao.

Jenkins, David, Black Zion: The Return of Afro-Americans and West Indians to Africa, Londres, Wildwood House, 1975.

Kayser, Manfred, et al., «Y Chromosome STR Haplotypes and the Genetic Structure of U.S. Populations of African, European, and Hispanic Ancestry», Genome Research, XIII (Nueva York, 2003): 624-634.

Larrazábal Blanco, Carlos, Los negros y la esclavitud en Santo Domingo, Santo Domingo, Librería La Trinitaria, 1998.

Livi Bacci, Massimo, Conquista. La distruzionedegli indios americani, Boloña, Il Mulino, 2009.

Marquese, Rafael de Bivar, «A dinámica da escravidáo no Brasil: Resistencia, tráfico negreiro e alforrias, sáculos XVII a XIX», Novos Estudos-CEBRAP, 74/1 (Rio de Janeiro, 2006): 107-123.

Matibag, Eugenio, Haitian-Dominican Counterpoint, Gordonsville, Virginia, Palgrave Macmillan, 2003.

Matory, J. Lorand, «The English Professors of Brazil: On the Diasporic Roots of the Yoruba Nation», Comparative Studies in Society and History, XLI/1 (Cambridge, 1999): 72-103. 
Miller, Ivor, Voice of the Leopard: African Secret Societies and Cuba, Jackson, University Press of Mississippi, 2009.

Miller, Paul G., Historia de Puerto Rico, Nueva York, Rand McNally, 1922.

Moya Pons, Frank, The Dominican Republic: A National History, Princeton, Markus Wiener, 1998.

Moya, José C., «Immigration, Development, and Assimilation in the United States in a Global Perspective, 1850-1930», Studia Migracyijne, XXXV/3 (Varsovia, 2009): 89-104.

Moya, José C. (ed.), Handbook of Latin American History, Nueva York, Oxford University Press, 2011.

Moya, José C., «Spanish immigration in Cuba and Argentina», Samuel Baily y Eduardo Miguez (eds.), Mass Migration to Modern Latin America, Wilmington, Scholarly Resources, 2003, 9-28.

Naranjo Orovio, Consuelo y García González, Armando, Racismo e inmigración en Cuba en el siglo XIX, Aranjuez, Doce Calles, 1996.

Newson, Linda A. y Minchin, Susie, From Capture to Sale: The Portuguese Slave Trade to Spanish America in the early Seventeenth Century, Leiden, Brill, 2007.

Nwokeji, G. U., «African Conceptions of Gender and the Slave Trade», William and Mary Quarterly, LVIII/1 (Williamsburg, 2001): 47-68.

O'Reggio, Trevor, Between Alienation and Citizenship: The Evolution of Black West Indian Society in Panama, 1914-1964, Lanham, MD, University Press of America, 2006.

Ortiz, Fernando, Hampa afro-cubana. Los negros esclavos; estudio sociológico y de derecho público, La Habana, Revista bimestre cubana, 1916.

Pena, Sergio D. J. et al., «The Genomic Ancestry of Individuals from Different Geographical Regions of Brazil is More Uniform Than Expected», PLoS ONE, VI/2 (San Francisco y Cambridge, 2011): http://www.plosone.org/article/info: doi/10.1371/journal.pone.0017063.

Pérez, Gerson Javier, Dimensión espacial de la pobreza en Colombia, Cartagena, Centro de Estudios Económicos Regionales, 2005.

Pérez, Louis A., To Die in Cuba: Suicide and Society, Chapel Hill, University of North Carolina Press, 2005.

Pétré-Grenouilleau, Olivier (ed.), From Slave Trade to Empire: Europe and the Colonisation of Black Africa, Londres, Routledge, 2004.

Putnam, Lara, The Company They Keep: Migrants and the Politics of Gender in Caribbean Costa Rica, 1870-1960, Chapel Hill, University of North Carolina Press, 2002. 
Ratelband, Klass, Os holandeses no Brasil e na Costa Africana, 1600-1650, Lisboa, Vega, 2003.

Reis, Joao y Klein, Herbert, «Slavery in Brazil», José C. Moya (ed.), Handbook of Latin American History, Nueva York, Oxford University Press, 2011: 181-211.

Reis, Joao, Slave rebellion in Brazil: the Muslim uprising of 1835 in Bahia, Baltimore, Johns Hopkins University Press, 1993.

Rodrigues, Jaime, Da costa a costa. Escravos, marinheiros e intermediários do tráfico negreiro de Angola ao Rio de Janeiro, 1780-1860, Sao Paulo, Companhia das Letras, 2005.

Rodríguez Morel, Genaro, «Esclavitud y vida rural en las plantaciones azucareras de Santo Domingo, siglo XVI», Anuario de estudios americanos, XLIX (Sevilla, 1992): 89-117.

Routon, Kenneth, «Open the Roads! Religious Sensibilities of Power and History in Havana, Cuba», Tesis doctoral, Southern Illinois University, 2006.

Schwartz, Stuart «The Historiography of Early Modern Brazil», José C. Moya (ed.), Handbook of Latin American History, Nueva York, Oxford University Press, 2011, 98-131.

Silié, Rubén, «Esclavitud y prejuicio de color en Santo Domingo», Boletín de Antropología Americana, XX (México, 1989):163-170.

Sosa, Enrique, Los Ñáñigos, La Habana, Ediciones Casa de las Américas, 1982.

Verger, Pierre, Flux et refluxed la traite des nègres entre le golfe de Bénin et Bahia de Todos os Santos du xvii au xix siècle, Paris, Mouton, 1968.

Vidal Luna, Francisco y Klein, Herbert, Slavery and the Economy of São Paulo, 1750-1850, Stanford, Stanford University Press, 2003.

Vidal Ortega, Antonino, Cartagena de Indias y la región histórica del Caribe, 15801640, Sevilla, CSIC, Escuela de Estudios Hispanoamericanos, 2008.

Vila Vilar, Eriqueta, Hispanoamérica y el comercio de esclavos, Sevilla, 1977.

Warner-Lewis, Maureen, Central Africa in the Caribbean: Transcending Time, Transforming Cultures, Kingston, University of the West Indies Press, 2003.

West-Durán, Alan (ed.), African Caribbeans: A Reference Guides, Westport, Greenwood, 2003.

Wright, John, The Trans-Saharan Slave Trade: History and Society of the Islamic World, Londres, Routledge, 2007.

Fecha de recepción: 24 de mayo de 2011

Fecha de aceptación: 7 de marzo de 2012 


\section{African migration and social formation in the Americas, $1500-2000$}

Around 11 million Africans reached the New World between 1500 and 1866 in what constitutes the first massive transoceanic migration in the history of humanity. This article approaches that movement from the perspective of the history of migrations and socio-racial formations in the Americas. The first part establishes the origins, timing, and geographic distribution of the arrivals using a database with information on some 35,000 slave ship voyages. We go on to analyze how this determined the demographic impact, socio-economic development, African cultural presence, adaptation and acculturation strategies, and the construction of racial taxonomies and identities in the receiving regions.

KeY words: Migration; Americas; Africa; slavery; race. 